\title{
Self-compatible Seedlings of the Cutleaf Hazelnut
}

\author{
Shawn A. Mehlenbacher and David C. Smith \\ Dept. of Horticulture, 4017 Agricultural and Life Sciences Building, Oregon \\ State University, Corvallis, OR 97331
}

Additional index words. filbert, Corylus avellana, fluorescence microscopy, pollen-stigma incompatibility, blank nuts

\begin{abstract}
The cutleaf hazelnut [Corylus avellana L. f. heterophylla (Loud.) Rehder] is an ornamental form with strongly dissected leaf morphology. Its stigmas express incompatibility allele $S_{20}$ but none of the other $25 \mathrm{~S}$-alleles was detected with fluorescence microscopy. Three seedlings from a cross of the cutleaf hazelnut and VR6-28 lacked $S_{20}$ and were investigated further. Each expressed an allele from the parent VR6-28 $\left(S_{2} S_{26}\right), S_{26}$ in OSU 562.031 and OSU 562.048 and $S_{2}$ in OSU 562.049. $S_{2}$ and $S_{26}$ are low in the dominance hierarchy, so we expected the new allele from the cutleaf hazelnut to be expressed in their pollen. Unexpectedly, fluorescence microscopy showed that pollen of all three selections was compatible on their cutleaf parent and on each other, and furthermore, self-pollinations showed the excellent germination and long parallel tubes in the styles that are typical of a compatible pollination. Controlled self- and cross-pollinations in the field verified the self-compatibility of two selections. Cluster set for self-pollinations was very high $\mathbf{( 7 5 - 9 0 \% )}$ and within the range observed for compatible cross-pollinations. Furthermore, the frequency of blank nuts was low $(<10 \%)$. The second allele in the cutleaf hazelnut is designated $S_{28}$, and its presence in seedlings of 'Cutleaf' is indicated by the absence of $S_{20}$. Controlled pollinations in the field also showed that selection OSU 562.069 $\left(\mathrm{S}_{2} \mathrm{~S}_{28}\right)$ from the cross 'Cutleaf' × 'Redleaf \#3' was self-compatible. Fluorescence microscopy showed that two additional seedlings were selfincompatible [OSU $367.052\left(S_{1} S_{28}\right)$ and OSU $\left.367.076\left(S_{6} S_{28}\right)\right]$ while a third [OSU 706.071 $\left.\left(\mathrm{S}_{9} \mathrm{~S}_{28}\right)\right]$ was self-compatible. Self-compatibility may be limited to genotypes that combine $\mathrm{S}_{28}$ with a second allele that is low in the dominance hierarchy.
\end{abstract}

The cutleaf hazelnut [Corylus avellana L. f. heterophylla (Loud.) Rehder] has an unusual leaf morphology that makes it desirable as an ornamental form. Here we refer to it as cutleaf. Compared to standard European hazelnut cultivars, its leaves are more deeply dissected and more sharply toothed. The form appears to be represented in collections and in commerce by a single clone that was first described as Corylus urticifolia by Noisette in 1825 (Rehder, 1949). The trait is under the control of a single locus at which cutleaf genotypes are homozygous recessive (Mehlenbacher and Smith, 1995). The cutleaf hazelnut produces almost no viable pollen, and so must be used as a female parent in controlled pollinations. The cutleaf hazelnut sets many blanks (nuts lacking kernels); typically half are blank. Furthermore, it has a strong tendency to produce heavy crops in alternate years and is highly susceptible to bud mites (primarily Phytoptus avellanae Nal.). The breeding of a new hazelnut that combines the cutleaf trait with a low frequency of blank nuts and resistance to bud mites and eastern filbert blight caused by Anisogramma anomala (Peck) E. Muller would represent a significant improvement in this ornamental form.

Hazelnut cultivars are diploid $(2 \mathrm{n}=2 \mathrm{x}$ $=22$ ) and self-incompatible, the reaction determined by a single $\mathrm{S}$ locus with multiple alleles (Thompson, 1979). Both alleles in a cultivar or selection are expressed in the stig-

Received for publication 15 Dec. 2005. Accepted for publication 15 Dec. 2005.

${ }^{1}$ E-mail mehlenbs@hort.oregonstate.edu. mas. One or both alleles are expressed in the pollen, depending on their placement in the dominance hierarchy (Mehlenbacher, 1997b). Fluorescence microscopy is used to identify the alleles present in cultivars and selections. In an incompatible cross, pollen germination is often reduced. Pollen grains that germinate produce short tubes that fail to penetrate the stigmatic surface, and many of these terminate in a pronounced bulb. In contrast, compatible pollen germinates well, the pollen tubes penetrate the stigmatic surface, and produce a mass of long parallel tubes in the styles. Nearly all cultivars are highly self-incompatible, and less than $10 \%$ of self-pollinated flowers develop into nut clusters. Previous reports of self-compatibility in hazelnut (usually partial or inconsistent over years) include those by Stritzke (1962), Modic (1971) and Makhno (1983). Mehlenbacher and Smith (1991) reported partial self-compatibility in 'Tombul' and 'Montebello', and in four of seven seedlings from the cross 'Montebello' $\times$ 'Compton'. However, self-pollination of these partially self-compatible types resulted in $40 \%$ fewer nuts per cluster and almost twice as many blanks as cross-pollination. Commercial orchards of cultivars with this level of partial self-compatibility would require pollinizers. Partial self-compatibility was also reported in some accessions of $C$. californica Marsh. and C. colurna L., but was often associated with a higher frequency of blanks (Erdogan and Mehlenbacher, 2001). In this paper, we report a high level of self-compatibility in seedlings of the cutleaf hazelnut that is not associated with a high frequency of blank nuts.
Several seedlings of the cutleaf hazelnut (Table 1) were used in fluorescence microscopy studies. Eight of these seedlings resulted from open-pollination of the cutleaf hazelnut, and eight resulted from controlled crosses of the cutleaf hazelnut with four different pollen parents. Selections OSU 562.048 and OSU 562.049, from a cross of 'Cutleaf' $\times$ VR 6-28, were used for controlled self- and cross-pollinations in 2001 and 2002. OSU 562.069, a selection from 'Cutleaf' $\times$ 'Redleaf \#3', was used in controlled pollinations in 2004 . VR 6-28 is from a cross of 'Riccia di Talanico' $\times$ 'Gasaway'. 'Redleaf \#3' is an open-pollinated seedling of 'Barcelona'; 'Rode Zeller' is believed to be the pollen parent and donor of red leaf color.

Fluorescence microscopy as described in detail by Mehlenbacher (1997a) was used to identify the S-alleles in seedlings and selections. An individual branch was emasculated and enclosed in a bag made of Tyvek housewrap, which is impervious to pollen. The first bag was enclosed in a second cloth bag. Pollen was collected from a series of testers, each of which expresses a single allele (Mehlenbacher, 1997a, 1997b).

Controlled pollinations were made annually in 2001-04 using standard techniques (Thompson et al., 1996) as part of the hazelnut breeding program at Oregon State University (OSU). For small crosses where few seedlings were desired, individual limbs were emasculated and bagged. For larger crosses, entire trees were emasculated and covered with a wooden frame that was then enclosed in white polyethylene. Pollen was collected in January and stored in cotton-stoppered vials in the freezer $\left(-18^{\circ} \mathrm{C}\right)$. Pollinations were made by hand in February when styles had emerged and were receptive. Female inflorescences were counted at the time of pollination. Nut clusters were harvested and counted in August. Percent cluster set was calculated as the ratio of nut clusters harvested to flowers pollinated. Blank nuts and nuts with kernels were counted separately. The percentage of blank nuts was calculated for each pollinated branch or tree as the number of blank nuts divided by the total number of nuts.

\section{Results and Discussion}

Fluorescence microscopy revealed that stigmas of the cutleaf hazelnut express incompatibility allele $S_{20}$ but none of the other 25 alleles. $\mathrm{S}_{20}$ was present in 10 of 14 seedlings from a controlled cross of 'Cutleaf' $\times$ VR628 but absent in four, indicating that cutleaf is heterozygous at the $\mathrm{S}$ locus (only three seedlings from this cross are listed in Table 1). Three of the four seedlings that lacked $\mathrm{S}_{20}$ were investigated further. One allele from the parent VR6-28 $\left(\mathrm{S}_{2} \mathrm{~S}_{26}\right)$ was identified in each selection, $\mathrm{S}_{26}$ in OSU 562.031 and OSU 562.048, and $\mathrm{S}_{2}$ in OSU 562.049. $\mathrm{S}_{2}$ and $\mathrm{S}_{26}$ are low in the dominance hierarchy Mehlenbacher, 1997b), so we expected the new allele, designated $\mathrm{S}_{28}$, from 'Cutleaf' to be expressed in 
their pollen. As expected, when pollen of these selections was placed on female inflorescences of testers expressing all known $\mathrm{S}$ alleles, all combinations were compatible. Unexpectedly, however, fluorescence microscopy showed that pollen of all three selections was compatible on their parent 'Cutleaf' and on each other, and furthermore, self-pollinated flowers showed excellent pollen germination and long tubes growing parallel down the styles, indicators of a compatible pollination.

Controlled self- and cross-pollinations were performed in the field to verify the apparent self-compatibility of two selections, OSU 562.048 and OSU 562.049 (Table 2). Self-pollination in 2001 resulted in very high cluster set ( $75 \%$ to $90 \%)$, as is routinely obtained from compatible cross-pollinations. The frequency of blank nuts was low $(<10 \%)$.

Table 1. Incompatibility alleles in seedlings of the cutleaf hazelnut [Corylus avellana L.f. heterophylla (Loud.) Rehder].

\begin{tabular}{lcl}
\hline Selection & S alleles $^{z}$ & Parentage \\
\hline 367.045 & 1520 & Cutleaf o.p. \\
367.049 & 2128 & Cutleaf o.p. \\
367.052 & 128 & Cutleaf o.p. \\
367.057 & 2021 & Cutleaf o.p. \\
367.063 & 128 & Cutleaf o.p. \\
367.065 & 120 & Cutleaf o.p. \\
367.071 & 620 & Cutleaf o.p. \\
367.076 & 628 & Cutleaf o.p. \\
$562.031^{y}$ & 2628 & Cutleaf $\times$ VR 6-28 \\
$562.048^{y}$ & 2628 & Cutleaf $\times$ VR 6-28 \\
$562.049^{y}$ & 228 & Cutleaf $\times$ VR 6-28 \\
562.062 & 620 & Cutleaf $\times$ Redleaf \#3 \\
$562.069^{y}$ & 228 & Cutleaf $\times$ Redleaf \#3 \\
562.077 & 620 & Cutleaf $\times$ Redleaf \#3 \\
706.036 & 920 & Cutleaf $\times$ Aurea $($ C. avellana L. var. aurea Kirchn. $)$ \\
706.037 & 628 & Cutleaf $\times$ Aurea $($ C. avellana L. var. aurea Kirchn.) \\
706.049 & 320 & Cutleaf $\times$ Pendula (C. avellana L. var. pendula Dipp.) \\
$706.071^{y}$ & 928 & Cutleaf $\times$ Pendula (C. avellana L. var. pendula Dipp. $)$ \\
\hline
\end{tabular}

${ }^{2}$ The presence of $\mathrm{S}_{28}$, the second allele in the cutleaf hazelnut, is indicated by the absence of $\mathrm{S}_{20}$. Italicized alleles are expressed in the pollen.

${ }^{y}$ Self-compatible. Fluorescence microscopy indicated that five selections were self-compatible. The selfcompatibility of three selections was verified by controlled pollinations in the field.

Table 2. Cluster set and frequency of blank nuts in controlled cross- and self-pollinations of hazelnuts (Corylus avellana) for the period 2001-04. Values are means \pm standard deviation for that set of pollinations.

\begin{tabular}{lcccc}
\hline Year & Combination & $\begin{array}{c}\text { No. of } \\
\text { pollinations }\end{array}$ & $\begin{array}{c}\text { Cluster set }(\%)^{\mathrm{y}} \\
(\text { mean } \pm \text { SD) }\end{array}$ & $\begin{array}{c}\text { Blank nuts }(\%)^{\mathrm{x}} \\
(\mathrm{mean} \pm \mathrm{SD})\end{array}$ \\
\hline 2001 & Crosses in cages & 60 & $77.4 \pm 17.9$ & $9.0 \pm 5.0$ \\
& Crosses in bags & 15 & $70.1 \pm 21.2$ & $15.9 \pm 6.9$ \\
& 562.048 selfed & 2 & $75.9 \pm 20.3$ & $4.3 \pm 0.7$ \\
2002 & 562.049 selfed & 2 & $90.0 \pm 6.7$ & $8.8 \pm 2.0$ \\
& Crosses in cages & 31 & $76.4 \pm 1.5$ & $8.5 \pm 5.2$ \\
& Crosses in bags & 12 & $76.3 \pm 15.0$ & $9.7 \pm 5.3$ \\
& 562.048 selfed & 2 & $82.7 \pm 4.3$ & $4.0 \pm 0.9$ \\
& 562.048 crossed & 3 & $76.5 \pm 11.9$ & nd $^{\mathrm{w}}$ \\
2003 & 562.049 selfed & 2 & $82.9 \pm 6.1$ & $6.4 \pm 0.9$ \\
& 562.049 crossed & 4 & $74.0 \pm 14.5$ & nd \\
& Crosses in cages & 38 & $56.1 \pm 22.2$ & $14.6 \pm 8.9$ \\
& Crosses in bags & 13 & $62.7 \pm 26.5$ & $9.8 \pm 8.0$ \\
& Crosses in cages & 48 & $73.1 \pm 21.4$ & $6.5 \pm 5.1^{\mathrm{v}}$ \\
& Crosses in bags & 22 & $63.1 \pm 24.5$ & $6.9 \pm 3.9^{\mathrm{v}}$ \\
& 562.069 selfed & 2 & $79.7 \pm 23.3$ & $4.7 \pm 4.7$ \\
& 562.069 crossed & 2 & $68.5 \pm 20.4$ & $10.9 \pm 1.4$ \\
\hline
\end{tabular}

${ }^{\mathrm{z}}$ Controlled pollinations were made on caged trees enclosed by a wooden frame covered with white polyethylene, or on individually bagged branches.

${ }^{y}$ Cluster set is the ratio of nut clusters harvested to female inflorescences pollinated.

xBlank nuts is the ratio of blank nuts to total nuts harvested.

"Not determined.

'In 2004, blank nuts were counted in 20 of 48 crosses in cages and 12 of 22 crosses in bags. ible. Because of self-compatibility, presence of the new allele $\mathrm{S}_{28}$ in seedlings of 'Cutleaf' is indicated by the absence of $\mathrm{S}_{20}$ rather than the reduced germination, short pollen tubes, and pronounced bulbs that are typical of an incompatible pollination. The five self-compatible selections that we identified combine the new allele from the cutleaf hazelnut $\left(\mathrm{S}_{28}\right)$ with a second allele that is low on the dominance hierarchy $\left(\mathrm{S}_{2}, \mathrm{~S}_{9}\right.$, or $\left.\mathrm{S}_{26}\right)$. In contrast, selections that combine $S_{28}$ with alleles higher on the dominance hierarchy $\left(\mathrm{S}_{1}\right.$ or $\left.\mathrm{S}_{6}\right)$ are selfincompatible. The identification of seedlings with $\mathrm{S}_{28}$ combined with other alleles would be useful in determining which pairs of alleles result in self-compatibility.

The level of self-compatibility in these selections and the low frequency of blank nuts observed when self-pollinated indicates that they are fully self-compatible. This represents a significant improvement over the partial self-compatible previously identified in 'Tombul' and 'Montebello'. If new cultivars are developed that combine this source of self-compatiblity with other desirable traits, it may be possible to plant orchards of a single cultivar, as pollenizers would not be needed if the cultivars were homogamous. It would also allow homeowners to plant and harvest nuts from a single tree, and would thus be especially useful for ornamental hazelnuts.

\section{Literature Cited}

Erdogan, V. and S.A. Mehlenbacher. 2001. Incompatibility in wild Corylus species. Acta Hort. 556:163-169.

Makhno, V.G. 1983. Some aspects of the biology of Corylus in Sochi. Subtropicheskie Kul'tury 1983(3):130-140.

Mehlenbacher, S.A. 1997a. Testing compatibility of hazelnut crosses using fluorescence microscopy. Acta Hort. 445:167-171.

Mehlenbacher, S.A. 1997b. Revised dominance hierarchy for S-alleles in Corylus avellana L. Theor. Appl. Genet. 94:360-366.

Mehlenbacher, S.A. and D.C. Smith. 1991. Partial self-compatibility in 'Tombul' and 'Montebello' hazelnut. Euphytica 56:231-236.

Mehlenbacher, S.A. and D.C. Smith. 1995. Inheritance of the cutleaf trait in hazelnut. HortScience 30:611-612.

Modic, D. 1971. A contribution to the study of self-fertility in the hazel. Zbornik Biotechniske Facultete Univerze v Ljubljana Kmetijstvo 18:119-126.

Rehder, A. 1949. Bibliography of cultivated trees and shrubs hardy in the cooler temperate regions of the northern hemisphere. Arnold Arboretum Harvard Univ., Jamaica Plain, Mass.

Stritzke, S. 1962. Untersuchungen über die befruchtungsbiologischen Verhältnisse bei HaselnussSorten unter besonderer Berücksichtigung ökologischer Verhaältnisse. Archiv für Gartenbau 1962(10):573-608.

Thompson, M.M. 1979. Genetics of incompatibility in Corylus avellana L. Theor. Appl. Genet. 54:113-116.

Thompson, M.M., H.B. Lagerstedt, and S.A. Mehlenbacher. 1996. Hazelnuts, p. 125-184. In: J. Janick and J.N. Moore (eds.). Fruit breeding. vol. 3. Nuts. John Wiley \& Sons, New York. 